\title{
Acute normovolemic hemodilution in combination with tranexamic acid is an effective strategy for blood management in lumbar spinal fusion surgery
}

Yang $\mathrm{Li}^{1}$, Yan Zhang ${ }^{1}$ and Xiutong Fang ${ }^{2^{*}}$

\begin{abstract}
Background: The retrospective study was designed to compare the effectiveness and safety of acute normovolemic hemodilution (ANH), tranexamic Acid (TXA), and a combination of ANH and TXA in lumbar spinal fusion surgery.

Methods: Data of 120 patients underwent multi-level posterior spinal fusion for treating degenerative lumbar disease between June 2013 and December 2017 was collected, retrospectively. Four treatment strategies were enrolled, including ANH, TXA, a combination of ANH and TXA, and without any patient blood management. Intraoperative blood loss, hemoglobin and PCV at the end of surgery and at the postoperative first day, and postoperative drain collection, and intraoperative and postoperative transfusion and rate of transfusion were also collected.

Results: Intraoperative blood loss and postoperative drain collection of the TXA group, ANH combined with TXA group were statistically lower than those in the control group and ANH group $(P<0.05)$. Intraoperative and postoperative transfusion amount and rate of intra-operative allogenic transfusion of the ANH group, TXA group, and ANH combined with TXA group were statistically lower than those of the control group $(P<0.05)$. Hemoglobin and PCV at postoperative the first day in the ANH group, TXA group, and ANH combined with TXA group were significant higher than those in the control group $(P<0.05)$. The combination of TXA and ANH group achieved the lowest intraoperative blood loss, postoperative drain collection and allogenic transfusion rate.
\end{abstract}

Conclusion: A combination of TXA and ANH might be an effective strategy for reducing the rate of transfusion and blood loss in patients underwent lumbar spinal fusion surgery.

Keywords: Lumbar spinal fusion surgery, Acute normovolemic hemodilution, Tranexamic acid

\section{Background}

Lumbar spinal fusion surgery is designed to decrease pain generated from the degenerative vertebral segments by stopping the motion of the joint. During perioperative periods of the spinal reconstructive surgery, massive

\footnotetext{
*Correspondence: fangxiutongsp@163.com

${ }^{2}$ Department of Orthoapedic Surgery, Beijing Shijitan Hospital, Capital Medical University, NO.10, Tieyi Road, Haidian District, Beijing 100038, China

Full list of author information is available at the end of the article
}

blood loss is inevitable and most patients in the surgery require allogeneic blood transfusion to avoid development of postoperative anemia, severe hypotension, metabolic acidosis, infections, acute lung injury, and cardiac arrest [1]. Although various blood-conservation interventions have been put forward, blood transfusion is still needed among lots of patients. Intraoperative and postoperative hemorrhage would cause the risks of infectious diseases transmission, postoperative infection, and immune modulation effects introduced by allogeneic

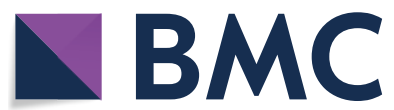

(c) The Author(s) 2022. Open Access This article is licensed under a Creative Commons Attribution 4.0 International License, which permits use, sharing, adaptation, distribution and reproduction in any medium or format, as long as you give appropriate credit to the original author(s) and the source, provide a link to the Creative Commons licence, and indicate if changes were made. The images or other third party material in this article are included in the article's Creative Commons licence, unless indicated otherwise in a credit line to the material. If material is not included in the article's Creative Commons licence and your intended use is not permitted by statutory regulation or exceeds the permitted use, you will need to obtain permission directly from the copyright holder. To view a copy of this licence, visit http://creativecommons.org/licenses/by/4.0/. The Creative Commons Public Domain Dedication waiver (http://creativeco mmons.org/publicdomain/zero/1.0/) applies to the data made available in this article, unless otherwise stated in a credit line to the data. 
blood, which are urgently needed to be solved [2-4]. In order to reduce bleeding during major spine surgery and achieve an optimal clinical outcome, various patient blood management strategies have been put forward to improve the clinical outcomes.

Several studies have evaluated the role of patient blood management strategies in blood loss and hemorrhage during and after spinal surgery [5-7], such as preoperative autologous blood donation, hypotensive anesthesia, acute hypervolemic hemodilution, acute normovolemic hemodilution (ANH), and intraoperative cell salvage system [8]. Acute hemodilution is easy to operate, less physiological interference with good effect and has become a common clinical blood saving method. ANH releases part of the intravascular volume before surgery, and reduces the preload, making it easier to obtain greater hemodilution effect, increasing the tolerance of blood loss, and protecting red blood cells. Carless et al. showed that ANH might recover up to $70 \%$ of the shed blood in orthopedic surgery and significantly reduce the use of erythrocyte [9]. Subsequently, lots of literatures demonstrated that ANH is an effective alternative strategy [10, $11]$.

In recent years, Tranexamic acid (TXA) has been used in spine surgery extensively to reduce perioperative and postoperative loss. The perioperative use of TXA was shown to prevent intraoperative blood loss and reduction the need for blood transfusions in numerous studies [12-14]. Raksakietisak et al. found $15 \mathrm{mg} / \mathrm{kg}$ TXA could significantly reduce blood loss and transfusion in low-risk adults undergoing complex laminectomy [15]. A meta-analysis conducted by Yang et al. demonstrated that patients receiving perioperative TXA had a reduction of blood loss along with a statistically significant decrease in the need for blood transfusion [14]. A common concern surrounding the use of perioperative TXA is its potential to induce thromboembolic events, such as deep vein thrombosis and pulmonary embolism. However, this particular risk is very low to negligible. Although many literatures had assessed the use of TXA or ANH in spinal surgery, the conclusion still remains inconsistency.

Thus, this study aimed to compare the effectiveness and safety of ANH, TXA, and a combination of ANH and TXA in reducing blood transfusion in lumbar spinal fusion surgery. The results of this study might help researchers improving the understanding of different blood management strategies.

\section{Methods}

\section{Population and selection criteria}

This retrospective study was approved by our hospital institutional review board before its commencement. The data of 120 patients (age range, 55-70 years) underwent multi-level posterior spinal fusion ( $\geq 2$ levels) for treating degenerative lumbar disease between June 2013 and December 2017 were collected. Among the 120 patients, four types of patient blood management were included, including ANH group, TXA group, ANH combined TXA group, and control group (without patient blood management). Demographic information including age, sex, body mass index, height, duration of surgery, number of fused segments, and number of interbody fusion were collected.

The inclusion criteria included: (1) Patients aged 50-70 years old who were diagnosed as degenerative lumbar disease and without allergy to TXA; (2) Patients underwent multi-level posterior spinal fusion ( $\geq 2$ levels) through a posterior midline approach; (3) Patients were treated with ANH, TXA, a combination of ANH and TXA, or without patient blood management. The exclusion criteria of patients enrolled included: (1) patients with liver cirrhosis, seriouscardiac disease, chronic renal failure, cancer, a history of thromboembolic disease (deep vein thrombosis, ischemic heart disease, pulmonary embolism, transient ischemic attack, strokes, or subarachnoid hemorrhage), bleeding disorders, hypercoagulation status, disseminated intravascular coagulation and pregnancy; (2) patients receiving antiplatelet and/or anticoagulant therapy at the time of the study; (3) patients with hematocrit $<35 \%$ and hemoglobin $<11 \mathrm{~g} /$ $\mathrm{dL}$; (4) patients with abnormal coagulant function or vascular diseases before surgery; (5) patient with New York classification > grade II, or American society of anesthesiologists classification > grade II; and (6) patients with valvular heart diseases, arrhythmias, severe pulmonary, hepatic and renal dysfunction, tumor disease or metastasis and (7) patients underwent minimally invasive spine surgery.

\section{Surgical technique}

Both $300 \mathrm{U} / \mathrm{kg}$ erythropoietin and $500 \mathrm{mg} / \mathrm{ml}$ iron sucrose were applied per week for 4 weeks in patients with hemoglobin $<110 \mathrm{~g} / \mathrm{L}$ in the preparation of operation. All patients underwent a similar operative technique of lumbar spinal fusion surgery. Patients were placed in a prone position on the operating table under general anesthesia. Through posterior midline skin incision, subperiosteal exposure of respective levels done. Pedicle screws were placed with free hand technique and connecting rods were installed. After resection of the laminae and removal of the corresponding disc transforaminally, a cage filled with autogenous bone graft was obliquely placed into intervertebral disc space. Radiography was taken to confirm the pedicle screws and cage position. After achieving hemostasis, negative pressure drainage was placed, and a layer to layer suture was 
carried out to close the wound. All wounds were closed with negative suction drain (Fig. 1).

\section{Blood management method}

For patients in ANH group, intraoperative autologous transfusion was performed with the Elmed 500 (Medtronics, Denver, CO, USA). The intraoperative autologous transfusion device was used for each case, and blood would be returned to the patient if there was a sufficient volume to process. Hemodilution was accomplished by the removal of artery blood from femoral artery after induction and intubation. The approximate volume of blood withdrawn was determined based on the estimated blood volume, preoperative hematocrit, and desired hematocrit. The blood with anticoagulant was collected in a fenwal autologous blood complications start occurring. ABL was calculated using the following formula:

$$
\mathrm{ABL}=\mathrm{EBV} *(\mathrm{Hi}-\mathrm{Hf}) \mathrm{Hi} .
$$

where ABL indicates allowable blood loss, EBV indicates estimated blood volume, $\mathrm{Hi}$ indicates Initial hematocrit and $\mathrm{Hf}$ indicates final hematocrit;

Traditionally, EBV for an adult male $=75 \mathrm{~mL} / \mathrm{kg}$, EBV for an adult female $=65 \mathrm{~mL} / \mathrm{kg}$.

Blood transfusion would be needed if blood loss exceeded the ABL. At the end of the surgery, the blood soaked swabs were weighed using an electronic weighing scale. The amount of blood in the suction apparatus and the amount of saline were recorded. Total amount of blood loss was calculated using the following formula:

Total amount of blood loss $=$ \{amount of fluid collected in suction apparatus (mL)

-amount of saline $(\mathrm{mL})$

+ amount of blood content in weighed swabs $(\mathrm{mL})\}$.

collection kit (Baxter, Baxter health Corporation, Deerfield, IL, USA). The targeted bleeding volume was 10\%-15\% of total blood volume according to the formula: in male, blood volume $=$ height $\times 28.5+$ weight $\times 31.6-2820$; and in female: blood volume $=$ height $\times 16.25+$ weight $\times 38.46-$ 1369. Total blood volume $=$ weight of blood volume $/ 1.060$ [13]. The collected blood was stored at $0-4{ }^{\circ} \mathrm{C}$. The blood was replaced with $6 \%$ hydroxyethyl starch $(130 / 0.4)$ in equal volume. After that, hypervolemic treatment was applied with 6\% hydroxyethyl starch (130/0.4) and $10 \mathrm{ml} /$ $\mathrm{kg}$ lactated ringer's solution (equal to $20 \%$ of total blood volume) within $30 \mathrm{~min}$. Then, norepinephrine and phenylephrine were applied to maintain mean arterial blood pressure below $20 \%$ of the basal blood pressure. During the operation, autologous blood transfusion would be performed when hemoglobin was lower than 8-9 $\mathrm{g} / \mathrm{L}$ or packed cell volume $(\mathrm{PCV})<24-27 \%$, and homologous blood would be used when necessary. After surgery, iron supplementation was implemented with $500 \mathrm{mg} / \mathrm{ml}$ iron sucrose per week.

All patients in the TXA group were given a dose of $15 \mathrm{mg} / \mathrm{kg}$ of TXA (Transamin; Daiichi Pharmaceutical, Tokyo, Japan) before a skin incision was made, followed by $1 \mathrm{mg} / \mathrm{kg} / \mathrm{h}$ infusion till skin closure [16].

Patients in the control group received neither ANH or TXA or any other anti-fibrinolytic drug during the intraoperative period.

\section{Outcome evaluation}

\section{Blood loss estimation}

ABL is also referred to as maximum allowable blood loss as it marks the amount after which hemorrhage where $1 \mathrm{~g}$ blood equaled $1 \mathrm{~mL}$ blood.

Blood products would be transfused postoperatively if the value of hemoglobin/PCV significantly dropped $(<8 \mathrm{~g} / \mathrm{d})$ and the drain collection increased $(>500 \mathrm{~mL})$.

\section{Hematological indicators}

Blood routine indicators including hemoglobi, $\mathrm{PCV}$, and platelets were determined by automated hematology analyzer (Beckman coulter, CA, USA). Blood routing indicators were tested preoperatively, at the end of surgery and at the postoperative first day.

\section{Coagulation assay}

Activated partial thromboplastin time (APTT) is recorded as the time required for the formation of a stable clot in seconds in citrated plasma, with addition of factor XII activator and $\mathrm{CaCl} 2$. Prothrombin time (PT) is a blood test that measures the time from the liquid portion of blood to clot in the presence of sufficient concentration of calcium and tissue thromboplastin. International normalized ratio (INR) is derived from PT which is calculated as a ratio of the patient's PT to a control PT. APTT, PT and INR are hematological indices reflecting the coagulation status of patients. Blood was centrifuged at $3000 \mathrm{rpm}$ for $15 \mathrm{~min}$ for testing of APTT and $\mathrm{PT}$ according to standard procedures. Coagulation assays were performed preoperatively.

\section{Postoperative drain volume}

Postoperative drain outputs including deep and superficial drains were collected and recorded. 


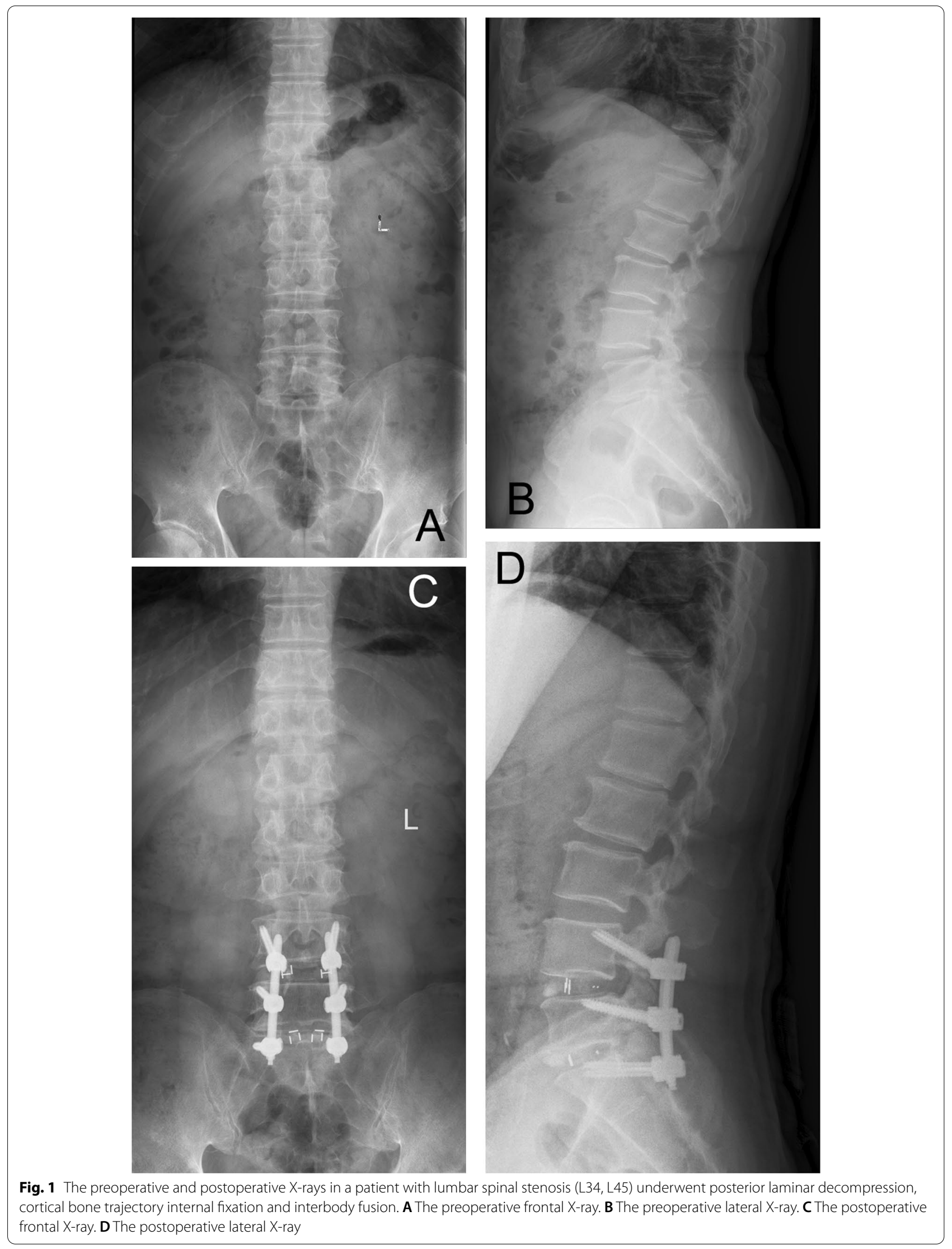




\section{Transfusion}

Intraoperative and postoperative transfusion amount and rate of transfusion were collected.

\section{Statistical analysis}

Continuous variables (including age, body weight, height, duration of surgery, body mass index number of fused segments, number of interbody fusion, hemoglobin, PCV, platelets, APTT, PT, INR, blood loss, drain, intraoperative allogenic transfusion amount and postoperative allogenic transfusion amount) were expressed as mean \pm standard deviation, and categorical data (including gender, intraoperative rate of allogenic transfusion and postoperative rate of allogenic transfusion) were presented as proportion or percentage. Analysis of variance and pearson $\chi^{2}$ test were used to estimate the difference of study parameters between groups for continuous variables and categorical data, respectively. All analyses were carried out using SPSS 20.0 (IBM, Armonk, NY, USA). A $P$ value $<0.05$ indicated statistical significance.

\section{Results}

\section{General results of enrolled patients}

The baseline characteristics of enrolled patients were shown in Table 1. Among the 120 patients enrolled, the most common diagnosis was lumbar spinal stenosis
(85 patients), followed by lumbar spondylolisthesis (21 patients), degenerative lumbar scoliosis (ten patients), and posterior revision surgery for failed lumbar degenerative disease (four patients). A total of 30 patients were included in each group. The mean age of patients in the ANH group, TXA group, ANH combined with TXA group, and control group were $(58.43 \pm 10.99)$ years, $(59.77 \pm 9.87)$ years, $(59.04 \pm 10.07)$ years, and $(60.02 \pm 9.01)$ years, respectively. The number of fused segments in the ANH group, TXA group, ANH combined with TXA group, and control group were $2.38 \pm 0.91, \quad 2.87 \pm 1.01, \quad 3.11 \pm 0.99$, and $2.99 \pm 1.12$, respectively. The number of interbody fusion in the ANH group, TXA group, ANH combined with TXA group, and control group were $1.28 \pm 0.97,1.34 \pm 1.02,1.61 \pm 1.31$, and $1.19 \pm 1.13$, respectively. No significant difference was found on the demographic parameters including patients' age, gender, body weight, height, duration of surgery, body mass index, number of fused segments and interbody fusion in all the groups $(P>0.05)$.

Preoperative baseline hematological and biochemical parameters among the four study groups were compared. As shown in Table 2, no significant difference was found on hemoglobi, PCV, platelets, APTT, PT, and INR among groups $(P>0.05)$.

Table 1 Demographic parameters and duration of surgery among different study groups

\begin{tabular}{llllll}
\hline Parameters & ANH $(\boldsymbol{N}=\mathbf{3 0})$ & TXA $(\boldsymbol{N}=\mathbf{3 0})$ & ANH + TXA $(\boldsymbol{N}=\mathbf{3 0})$ & Control $(\boldsymbol{N}=\mathbf{3 0})$ & Overall $\boldsymbol{P}$ value \\
\hline Age, years & $58.43 \pm 10.99$ & $59.77 \pm 9.87$ & $59.04 \pm 10.07$ & $60.02 \pm 9.01$ & 0.679 \\
Gender (female: male) & $14: 16$ & $13: 17$ & $16: 14$ & $15: 15$ & 0.294 \\
Body weight, kg & $60.12 \pm 4.65$ & $59.88 \pm 3.98$ & $61.65 \pm 5.07$ & $61.96 \pm 5.35$ & 0.109 \\
Height, cm & $171.10 \pm 6.03$ & $170.67 \pm 5.97$ & $172.02 \pm 6.01$ & $171.69 \pm 5.89$ & 0.410 \\
BMl & $21.98 \pm 2.27$ & $21.69 \pm 1.99$ & $22.02 \pm 2.02$ & $21.42 \pm 1.92$ & 0.757 \\
Duration of surgery, min & $189.64 \pm 35.89$ & $195.64 \pm 37.19$ & $200.16 \pm 36.97$ & $185.85 \pm 35.19$ & 0.578 \\
Number of fused segments & $2.38 \pm 0.91$ & $2.87 \pm 1.01$ & $3.11 \pm 0.99$ & $2.99 \pm 1.12$ & 0.428 \\
Number of interbody fusion & $1.28 \pm 0.97$ & $1.34 \pm 1.02$ & $1.61 \pm 1.31$ & $1.19 \pm 1.13$ & 0.356 \\
\hline
\end{tabular}

$B M I$ body mass index, ANH Acute normovolemic hemodilution, TXA Tranexamic acid

Table 2 Comparison of preoperative blood parameters among different study groups

\begin{tabular}{lrrrr}
\hline Preoperative Variables & \multicolumn{1}{l}{ ANH } & TXA & ANH+TXA & Control \\
\hline Hemoglobin, g/dL & $13.52 \pm 1.53$ & $12.99 \pm 1.47$ & $12.77 \pm 1.59$ & $13.02 \pm 1.46$ \\
PCV & $36.74 \pm 3.97$ & $37.93 \pm 4.23$ & $37.46 \pm 4.35$ & $38.27 \pm 4.08$ \\
Platelets & $2.98 \pm 0.74$ & $3.05 \pm 0.81$ & $3.01 \pm 0.83$ & 0.108 \\
APTT & $27.45 \pm 2.11$ & $28.01 \pm 3.07$ & $27.07 \pm 2.14$ & $27.89 \pm 2.65$ \\
PT & $15.07 \pm 2.05$ & $14.98 \pm 1.54$ & $15.01 \pm 1.61$ & $15.19 \pm 1.34$ \\
INR & $1.01 \pm 0.09$ & $1.10 \pm 0.19$ & $1.08 \pm 0.13$ & 0.879 \\
\hline
\end{tabular}

ANH Acute normovolemic hemodilution, TXA Tranexamic acid, APTT activated partial thromboplastin time, INR international normalized ratio, $P C V$ hematocrit or packed cell volume, $P T$ prothrombin time 
Table 3 Comparison of intraoperative blood loss and hematological indicators at the end of surgery among study groups

\begin{tabular}{lccccc}
\hline Intraoperative variables & ANH & TXA & ANH + TXA & Control & Overall $P$ value \\
\hline Blood loss, $\mathrm{mL}$ & $545.32 \pm 189.29$ & $378.72 \pm 96.57^{\mathrm{ab}}$ & $336.16 \pm 88.46^{\mathrm{ab}}$ & $578.44 \pm 201.81$ & $<0.001$ \\
Hemoglobin, $\mathrm{g} / \mathrm{dL}$ (at the end of surgery) & $12.07 \pm 1.21$ & $11.69 \pm 1.37$ & $11.94 \pm 1.71$ & $11.26 \pm 1.26$ & 0.195 \\
PCV (at the end of surgery) & $33.41 \pm 4.12$ & $32.67 \pm 3.43$ & $33.80 \pm 4.89$ & $31.98 \pm 4.27$ & 0.282 \\
Hemoglobin, $\mathrm{g} / \mathrm{dL}$ (at the postoperative first day) & $10.13 \pm 1.24^{\mathrm{a}}$ & $9.98 \pm 1.31^{\mathrm{a}}$ & $11.07 \pm 1.41^{\mathrm{abc}}$ & $8.63 \pm 1.63$ & 0.154 \\
PCV (at the postoperative first day) & $30.98 \pm 3.27^{\mathrm{a}}$ & $31.89 \pm 3.48^{\mathrm{a}}$ & $33.68 \pm 4.09^{\mathrm{abc}}$ & $29.02 \pm 3.06$ & 0.161 \\
\hline
\end{tabular}

Letter "a" indicated $P<0.05$ compared with control group, letter "b" indicated $P<0.05$ compared with ANH group, letter "c" indicated $P<0.05$ compared with TXA group, respectively

ANH Acute normovolemic hemodilution, TXA Tranexamic acid, PCV packed cell volume

\section{Comparison of intraoperative blood loss, hemoglobin and PCV}

Intraoperative blood loss and hemoglobin at the end of surgery among study groups were shown in Table 3 . The mean intraoperative blood loss in the ANH group, TXA group, ANH combined with TXA group, and control group were $(545.32 \pm 189.29) \mathrm{mL},(378.72 \pm 96.57)$ $\mathrm{mL},(336.16 \pm 88.464) \mathrm{mL}$, and $(578.44 \pm 201.81) \mathrm{mL}$, respectively. Intraoperative blood loss of the TXA group $(P=0.023)$ and the ANH combined with TXA group $(P=0.001)$ was statistically lower than those of the control group. Moreover, intraoperative blood loss in the ANH group was significantly higher than that in the TXA group $(P=0.0029)$ and the ANH combined with TXA group $(P=0.009)$. No significant difference was found between the TXA group and the ANH combined with TXA group $(P=0.190)$. Meanwhile, no significant difference was detected between the ANH group and the control group $(P=0.082)$.

Hemoglobin and PCV at postoperative the first day in the ANH group $(P=0.019$ and $P=0.032)$, TXA group $(P=0.025$ and $P=0.032)$, and ANH combined with TXA group $(P=0.019$ and $P=0.027)$ were significantly higher than those in the control group. Hemoglobin and PCV at postoperative the first day in the $\mathrm{ANH}$ combined with TXA group was statistically higher than those in the ANH group $(P=0.021$ and $P=0.025)$ and TXA group $(P=0.043$ and $P=0.041)$.

\section{Comparison of postoperative drain collection}

Postoperative drain collection comparison among study groups was shown in Table 4. Mean postoperative drain collection in the ANH group, TXA group,
ANH combined with TXA group, and control group were $\quad(360.00 \pm 120.54) \mathrm{mL}, \quad(260.40 \pm 109.58) \mathrm{mL}$, $(240.00 \pm 92.84) \mathrm{mL}$, and $(410.00 \pm 129.98) \mathrm{mL}$, respectively. Postoperative drain collection in the TXA group $(P=0.015)$ and the ANH combined with TXA group $(P=0.008)$ were significantly lower than those in the control group. Moreover, postoperative drain collection in the ANH group was significantly higher than that in the TXA group $(P=0.018)$ and the ANH combined with TXA group $(P=0.003)$. No significant difference was found between the TXA group and the ANH combined with TXA group $(P=1.003)$. Similarly, no significant difference was found between the ANH group and the control group $(P=0.778)$.

\section{Comparison of transfusion outcomes}

Comparison of intraoperative and postoperative transfusion and rate of transfusion among study groups was shown in Table 5. Intraoperative transfusion amount and rate of intraoperative allogenic transfusion of the $\mathrm{ANH}$ group $(P=0.007$ and $P=0.005)$, TXA group $(P=0.010$ and $P=0.030)$, ANH combined with TXA group $(P=0.001$ and $P=0.002)$ were statistically lower than those of the control group. Meanwhile, significant difference was found on intraoperative transfusion amount $(P=0.019, P=0.012$, and $P=0.024)$ and rate of intraoperative allogenic transfusion $(P=0.035, P=0.027$ and $P=0.014$ ) between the ANH group and the TXA group, the ANH group and the ANH combined with TXA group, the TXA group and the ANH combined with TXA group.

Similarly, postoperative transfusion amount and rate of postoperative allogenic transfusion of the ANH group

Table 4 Comparison of postoperative drain collection among study groups

\begin{tabular}{lllll}
\hline & ANH & TXA & ANH+TXA & Control \\
\hline Drain, $\mathrm{mL}$ & $360.00 \pm 120.54$ & $260.40 \pm 109.58^{\mathrm{ab}}$ & $240.00 \pm 92.84^{\mathrm{ab}}$ & $410.00 \pm 129.98$ \\
\hline
\end{tabular}

Letter "a" indicated $P<0.05$ compared with control group, letter "b" indicated $P<0.05$ compared with ANH group, respectively

ANH Acute normovolemic hemodilution, TXA Tranexamic acid 
Table 5 Comparison of intraoperative and postoperative transfusion amount and rate of transfusion among study groups

\begin{tabular}{llllll}
\hline Transfusion & ANH & TXA & ANH+TXA & Control & Overall $P$ value \\
\hline Intraoperative allogenic transfusion amount, $\mathrm{mL}$ & $182.21 \pm 43.55^{\mathrm{a}}$ & $251.21 \pm 53.52^{\mathrm{ab}}$ & $106.21 \pm 32.55^{\mathrm{abc}}$ & $447.21 \pm 232.55$ & $<0.001$ \\
Intraoperative rate of allogenic transfusion, $\%$ & $16.67^{\mathrm{a}}$ & $33.33^{\mathrm{ab}}$ & $6.67^{\mathrm{abc}}$ & 63.33 & $<0.001$ \\
Postoperative allogenic transfusion amount, $\mathrm{mL}$ & $81.36 \pm 13.11^{\mathrm{a}}$ & $105.21 \pm 14.69^{\mathrm{ab}}$ & $43.12 \pm 9.15^{\mathrm{abc}}$ & $143.21 \pm 24.57$ & $<0.001$ \\
Postoperative rate of allogenic transfusion, $\%$ & $6.67^{\mathrm{a}}$ & $13.33^{\mathrm{ab}}$ & $3.33^{\mathrm{abc}}$ & 20 & $<0.001$
\end{tabular}

Letter "a" indicated $P<0.05$ compared with control group, letter "b" indicated $P<0.05$ compared with ANH group, letter "c" indicated $P<0.05$ compared with TXA group, respectively

ANH Acute normovolemic hemodilution, TXA Tranexamic acid

$(P=0.037$ and $P=0.01)$, TXA group $(P=0.039$ and $P=0.013)$, ANH combined with TXA group $(P=0.006$ and $P=0.002$ ) was statistically lower than those in the control group. Meanwhile, significant difference was found on postoperative transfusion amount $(P=0.041$, $P=0.022$, and $P=0.013)$ and rate of postoperative allogenic transfusion $(P=0.03, P=0.022$ and $P=0.003)$ of the ANH group and TXA group, the ANH group and the ANH combined with TXA group, TXA group and the ANH combined with TXA group.

\section{Complications}

No serious intraoperative or postoperative complication, such as dural tear, infection, epidural hematoma formation, deep-vein thrombosis, pulmonary embolism, allergic reaction, renal failure, or cardiopulmonary complications was found in all four groups. Furthermore, no minor side effects associated with the use of TXA such as nausea, vomiting, headache, or diarrhea occurred in all groups.

\section{Discussion}

Lumbar spinal fusion surgery is one of the most commonly performed procedures of spine surgeries. There are various factors that either increase the risk of bleeding or require additional operative time in spine surgery, such as anatomical structure of spine, spongy vertebrae with its rich blood supply, and the fragile venous plexus wall that cannot self-contract after injury [17]. ANH and TXA were widely used in the spinal fusion surgery for blood management. However, the clinical outcomes remained controversial. Our data showed that intraoperative blood loss and postoperative drain collection of the TXA group and ANH combined with TXA group were significantly lower than those of the control group and ANH group. Intraoperative and postoperative transfusion amount and rate of intraoperative allogenic transfusion of the ANH group, TXA group, and ANH combined with TXA group were statistically lower than those of the control group. Hemoglobin and PCV at postoperative the first day in the ANH group, TXA group, and ANH combined with TXA group was significantly higher than those in the control group. The hemoglobin and PCV at postoperative first day in ANH combined with TXA group was statistically higher than the ANH group and TXA group. Thus, these data suggest implementation of ANH combined with TXA is an effective strategy for reducing the rate of transfusion in patients undergoing lumbar spinal fusion surgery.

Blood transfusion is crucial for radical surgery to avoid excessive bleeding. In past decades, ANH means blood withdrawal immediately before or after anesthetic induction, followed by dilution with colloids and/or crystalloids without reducing the circulating volume and then the circulating blood volume is supplemented with colloidal or crystal fluid and has been recommended to apply in surgeries with increased risk of bleeding [18]. ANH either achieves objective level of blood dilution, or avoids overloading circulation [10]. It could reduce the risk of hemolytic, allergic, pulmonary, immune-allergic reactions and acquisition of infectious-contagious diseases and can be obtained with a low operational cost [19]. In consistent with previous studies, we found no serious intraoperative or postoperative complications in all groups in this study.

TXA is a widely used synthetic fibrinolytic inhibitor. It can competitively inhibit the plasminogen activator and the adsorption of plasminogen to fibrin to prevent its activation and fibrin from being degraded by plasmin by binding lysine-binding sites of plasminogen. Moreover, it has the protective effect on platelets [20]. A dose of $15 \mathrm{mg} / \mathrm{Kg}$ TXA was intravenous injected at $15 \mathrm{~min}$ before skin incision was made followed by $1 \mathrm{mg} / \mathrm{Kg} / \mathrm{h}$ infusion till skin closure in our study.

The intraoperative blood loss in the TXA group, and the ANH and TXA combination group were $(378.72 \pm 96.57) \mathrm{mL}$ and $(336.16 \pm 88.464) \mathrm{mL}$, respectively, which was significantly lower than that in ANH group $[(545.32 \pm 189.29) \mathrm{mL}]$ and control group $[(578.44 \pm 201.81) \mathrm{mL}]$. Though ANH could reduce the risk of complications, this method is associated with increased blood loss as a result of autologous blood being withdrawn. Therefore, the blood loss of $\mathrm{ANH}$ 
group was comparable with that of control group in this study. TXA can decrease bleeding by acting on the fibrinolytic system [21]. Elwatidy et al. [13] reported a significant reduction in blood loss in patients who were administered TXA during spine surgery. Yagi et al. [5] showed that the TXA group had significantly less intraoperative blood loss and postoperative blood loss during posterior spinal fusion for the treatment of idiopathic scoliosis in adolescents. Based on a randomized double-blind placebo controlled study, Shakeri et al. [22] showed that TXA could reduce both intraoperative and immediate postoperative blood loss, decrease the need for packed cell transfusion, and reduce the duration of hospitalization after complex spinal surgeries. $\mathrm{Ni}$ et al. demonstrated that intravenous TXA can effectively and safely reduce blood loss and bleeding-related complications after high tibial osteotomy and was beneficial for the blood management. Furthermore, data showed tendency toward less postoperative bleeding drain in TXA group [23].

The hemoglobin and PCV at the end of surgery were not significantly different among groups in this study. This result was partly in argument with previous study [19], which found reduced hemoglobin in ANH group as compared to control group. The hemoglobin and PCV at the postoperative first day was significantly higher in ANH group than that in control group. This can be attributed to the improved blood microcirculation of $\mathrm{ANH}[24,25]$. In addition, the autologous blood in ANH group preserves the platelet function and thus provides platelets and clotting factors after returning back to body [25]. We could also noticed that combined use of both ANH and TXA provided better improvement of hemoglobin and $\mathrm{PCV}$ at the post postoperative fist day.

The intraoperative allogenic transfusion amount and rate as well as the postoperative allogenic transfusion amount and rate were significantly decreased compared with those in control group. This might be associated with the less loss of red blood cell mass during surgery and the return of fresh platelets and clotting factors at the end of surgery. This result is consistent with most of the previous studies [25-28]. Moreover, intraoperative transfusion amount, allogenic transfusion, and postoperative transfusion amount of patients treated by TXA combined ANH were statistically lower than that in patients treated by ANH or TXA alone, respectively. Thus, it is reasonable to believe that the administration of TXA could improve the ability of ANH in reducing the blood loss, improving the recovery of hemoglobin and PCV and decreasing the need for allogenic blood transfusion.

However, there are some limitations in this study. First, the sample size of this study is relatively small. Only 30 patients were analyzed in each group. Second, the follow-up study was not conducted to compare the longterm outcomes of these four groups. Third, this study is a retrospective study, the information and data included are not sufficient and therefore subgroup analysis and multi-variate analysis were unable to perform.

\section{Conclusion}

In conclusion, a combination of TXA and ANH might be a better choice for patients underwent lumbar spinal fusion surgery in reducing blood loss and the need for blood transfusion. However, further randomized double-blind study should be designed to verify the current conclusion.

\section{Abbreviations}

ANH: Acute normovolemic hemodilution; TXA: Tranexamic acid; PCV: Packed cell volume; APTT: Platelets, activated partial thromboplastin time; PT: Prothrombin time; INR: International normalized ratio; ABL: Allowable blood loss.

\section{Acknowledgements \\ None.}

Authors' contributions

$Y L$ designed the research, acquired data and analyzed data and drafted the manuscript. YZ performed statistical analysis. XF designed the research and revised manuscript for important intellectual content. All authors read and approved the final manuscript.

\section{Funding}

None.

Availability of data and materials

The data used to support the findings of this study are available from the corresponding author upon request.

\section{Declarations}

Ethical approval and consent to participate

This retrospective study was approved by our hospital institutional review board before its commencement.

Consent for publication

Not applicable.

Competing interests

The authors declare that they have no competing interest.

\section{Author details}

${ }^{1}$ Department of Thoracic Surgery, The First Hospital of Jilin University, Changchun 130021, China. ${ }^{2}$ Department of Orthoapedic Surgery, Beijing Shijitan Hospital, Capital Medical University, NO.10, Tieyi Road, Haidian District, Beijing 100038, China.

Received: 21 October 2021 Accepted: 21 January 2022

Published online: 05 February 2022

\section{References}

1. Elgafy H, Bransford RJ, McGuire RA, Dettori JR, Fischer D. Blood loss in major spine surgery: Are there effective measures to decrease massive hemorrhage in major spine fusion surgery? Spine (Phila Pa 1976). 2010;35(9 Suppl):S47-56. https://doi.org/10.1097/BRS.0b013e3181 d833f6. 
2. Winter SF, Santaguida C, Wong J, Fehlings MG. Systemic and topical use of tranexamic acid in spinal surgery: a systematic review. Global Spine J. 2016;6(3):284-95. https://doi.org/10.1055/s-0035-1563609.

3. Sert GS, Cavus M, Kemerci P, Bektas S, Demir ZA, Ozgok A, et al. The results of cardiac surgery in terms of patient blood management in our hospital. Turk J Anaesthesiol Reanim. 2019;47(5):402-6. https://doi.org/10.5152/ TJAR.2019.02058.

4. Visagie M, Qin CX, Cho BC, Merkel KR, Kajstura TJ, Amin RM, et al. The impact of patient blood management on blood utilization and clinical outcomes in complex spine surgery. Transfusion. 2019;59(12):3639-45. https://doi.org/10.1111/trf.15544.

5. Yagi M, Hasegawa J, Nagoshi N, lizuka S, Kaneko S, Fukuda K, et al. Does the intraoperative tranexamic acid decrease operative blood loss during posterior spinal fusion for treatment of adolescent idiopathic scoliosis? Spine (Phila Pa 1976). 2012;37(21):E1336-42. https://doi.org/10.1097/BRS. Ob013e318266b6e5.

6. Jerico C, Osorio J, Garcia-Erce JA, Pera M. Patient Blood Management strategies for iron deficiency anemia management in gastric cancer. Eur J Gastroenterol Hepatol. 2019;31(4):547-8. https://doi.org/10.1097/MEG 0000000000001383

7. Spahn DR. Patient blood management: What Else? Ann Surg. 2019:269(5):805-7. https://doi.org/10.1097/SLA.0000000000003186.

8. Saricaoglu F, Akinci SB, Celiker V, Aypar U. The effect of acute normovolemic hemodilution and acute hypervolemic hemodilution on coagulation and allogeneic transfusion. Saudi Med J. 2005;26(5):792-8.

9. Carless PA, Henry DA, Moxey AJ, O'Connell D, Brown T, Fergusson DA. Cell salvage for minimising perioperative allogeneic blood transfusion. Cochrane Database Syst Rev. 2010;4:CD001888. https://doi.org/10.1002/ 14651858.CD001888.pub4.

10. Parasa SK, Bidkar PU, Parida S. Acute normovolemic hemodilution to avoid blood transfusion during intracranial aneurysm surgery in a patient with atypical antibodies. Anesth Essays Res. 2016;10(1):136-8. https://doi. org/10.4103/0259-1162.161818.

11. Takekawa D, Saito J, Kinoshita H, Hashiba E, Hirai N, Yamazaki Y, et al. Acute normovolemic hemodilution reduced allogeneic blood transfusion without increasing perioperative complications in patients undergoing free-flap reconstruction of the head and neck. J Anesth. 2020;34(2):18794. https://doi.org/10.1007/s00540-019-02714-5.

12. Yoo JS, Ahn J, Karmarkar SS, Lamoutte EH, Singh K. The use of tranexamic acid in spine surgery. Ann Transl Med. 2019;7(Suppl 5):S172. https://doi. org/10.21037/atm.2019.05.36.

13. Elwatidy S, Jamjoom Z, Elgamal E, Zakaria A, Turkistani A, El-Dawlatly A. Efficacy and safety of prophylactic large dose of tranexamic acid in spine surgery: a prospective, randomized, double-blind, placebo-controlled study. Spine (Phila Pa 1976). 2008;33(24):2577-80. https://doi.org/10. 1097/BRS.0b013e318188b9c5.

14. Yang B, Li H, Wang D, He X, Zhang C, Yang P. Systematic review and meta-analysis of perioperative intravenous tranexamic acid use in spinal surgery. PLoS ONE. 2013;8(2): e55436. https://doi.org/10.1371/journal. pone.0055436.

15. Raksakietisak M, Sathitkarnmanee $B$, Srisaen $P$, Duangrat $T$, Chinachoti $T$ Rushatamukayanunt $P$, et al. Two doses of tranexamic acid reduce blood transfusion in complex spine surgery: a prospective randomized study. Spine (Phila Pa 1976). 2015;40(24):E1257-63. https://doi.org/10.1097/brs 0000000000001063

16. Soviero F, Geraci A, Termine S, Sanfilippo A, Maritano RM, D'Arienzo M, et al. Bleeding in orthopaedic surgery: the role of blood transfusion and erythropoietin alpha. Acta Biomed. 2010;81(2):125-9.

17. Markowitz MA, Waters JH, Ness PM. Patient blood management: a primary theme in transfusion medicine. Transfusion. 2014;54(10 Pt 2):2587. https://doi.org/10.1111/trf.12862.

18. Oppitz PP, Stefani MA. Acute normovolemic hemodilution is safe in neurosurgery. World Neurosurg. 2013;79(5-6):719-24. https://doi.org/10. 1016/j.wneu.2012.02.041.

19. Batista MFS, Costa CO, Vialle EN, Guasque J, Fiorentin JZ, Souza CS. Acute normovolemic hemodilution in spinal deformity surgery. Rev Bras Ortop (Sao Paulo). 2019;54(5):516-23. https://doi.org/10.1016/j.rbo.2018.02.004.

20. Wong J, El Beheiry H, Rampersaud YR, Lewis S, Ahn H, De Silva Y, et al. Tranexamic acid reduces perioperative blood loss in adult patients having spinal fusion surgery. Anesth Analg. 2008;107(5):1479-86. https://doi. org/10.1213/ane.0b013e3181831e44.
21. Benoni G, Fredin H. Fibrinolytic inhibition with tranexamic acid reduces blood loss and blood transfusion after knee arthroplasty: a prospective, randomised, double-blind study of 86 patients. J Bone Joint Surg Br. 1996;78(3):434-40.

22. Shakeri M, Salehpour F, Shokouhi G, Aeinfar K, Aghazadeh J, Mirzaei F, et al. Minimal dose of tranexamic acid is effective in reducing blood loss in complex spine surgeries: a randomized double-blind placebo controlled study. Asian Spine J. 2018;12(3):484-9. https://doi.org/10.4184/ asj.2018.12.3.484.

23. Peters A, Verma K, Slobodyanyuk K, Cheriyan T, Hoelscher C, Schwab $\mathrm{F}$, et al. Antifibrinolytics reduce blood loss in adult spinal deformity surgery: a prospective, randomized controlled trial. Spine (Phila Pa 1976). 2015;40(8):E443-9. https://doi.org/10.1097/BRS.0000000000000799.

24. Milam JD, Austin SF, Nihill MR, Keats AS, Cooley DA. Use of sufficient hemodilution to prevent coagulopathies following surgical correction of cyanotic heart disease. J Thorac Cardiovasc Surg. 1985;89(4):623-9.

25. Bansal N, Kaur G, Garg S, Gombar S. Acute normovolemic hemodilution in major orthopedic surgery. J Clin Orthop Trauma. 2020;11(Suppl 5):S844-8. https://doi.org/10.1016/j.jcot.2020.06.017.

26. Olsfanger D, Fredman B, Goldstein B, Shapiro A, Jedeikin R. Acute normovolaemic haemodilution decreases postoperative allogeneic blood transfusion after total knee replacement. Br J Anaesth. 1997;79(3):317-21. https://doi.org/10.1093/bja/79.3.317.

27. Naqash IA, Draboo MA, Lone AQ, Nengroo SH, Kirmani A, Bhat AR. Evaluation of acute normovolemic hemodilution and autotransfusion in neurosurgical patients undergoing excision of intracranial meningioma. J Anaesthesiol Clin Pharmacol. 2011;27(1):54-8.

28. Goldberg J, Paugh TA, Dickinson TA, Fuller J, Paone G, Theurer PF, et al. Greater volume of acute normovolemic hemodilution may aid in reducing blood transfusions after cardiac surgery. Ann Thorac Surg. 2015;100(5):1581-7. https://doi.org/10.1016/j.athoracsur.2015.04.135 (discussion 7)

\section{Publisher's Note}

Springer Nature remains neutral with regard to jurisdictional claims in published maps and institutional affiliations.

Ready to submit your research? Choose BMC and benefit from

- fast, convenient online submission

- thorough peer review by experienced researchers in your field

- rapid publication on acceptance

- support for research data, including large and complex data types

- gold Open Access which fosters wider collaboration and increased citations

- maximum visibility for your research: over $100 \mathrm{M}$ website views per year

At BMC, research is always in progress.

Learn more biomedcentral.com/submissions 